\title{
Evaluation of drought resistance in Iris germanica L. based on subordination function and principal component analysis
}

\author{
Wei Bo ${ }^{1,2}$, Baochun Fu², Guojie Qin², Guoming Xing ${ }^{1 *}$, Yuguo Wang ${ }^{3}$ \\ ${ }^{1}$ College of Horticulture, Shanxi Agricultural University, Taigu, Shanxi 030801, China, ${ }^{2}$ Institute of Horticulture, Shanxi Academy of Agricultural \\ Sciences, Taiyuan, Shanxi 030031, China, ${ }^{3}$ College of Agriculture, Shanxi Agricultural University, Taigu, Shanxi 030801, China
}

\section{A B S T R A C T}

Drought is one of the major environment stresses that have a wide range of impact on plants. In this study, seven physiological indexes including the content of soluble protein (SP), chlorophyll (Chl) and malondialdehyde (MDA), superoxide dismutase (SOD) and peroxidase (POD) activities, leaf relative water content (RWC), rate of water loss (RWL) from excised leaves were measured in leaves of Iris germanica before and after the drought treatment. It was found that the content of MDA and SP, POD and SOD activity increased, while RWL and RWC decreased in response to drought stress. Based on the subordinate function values of seven physiological indexes, seven single indexes were transformed into three principal components namely damage degree, active oxygen removal ability and moisture condition and the composite score (F value) of each iris variety was calculated by principal component analysis (PCA). Based on the F values, 10 iris cultivars could be divided into three groups by cluster analysis (CA): drought-resistance (2 varieties), medium drought-resistance (5 varieties), and low drought-resistance (3 varieties). Meanwhile, optimum regression equation was constructed. Therefore, this work provides a comprehensive and reliable method for evaluating drought resistance in the varieties of Iris germanica.

Keywords: Cluster analysis; Drought resistance; Iris germanica; Principal component analysis; Subordination function analysis

\section{INTRODUCTION}

As global climate is constantly changing, there are an increasing number of regions that have been affected by global warming. At present, nearly $40 \%$ of the land area around the world is faced with arid or semiarid conditions (Kawai et al., 2014; Parr et al., 1989). By 2025, drylands may occupy $48 \%$ of the global land surface (Huang et al., 2016). It is very hot and rarely rains all the year round in these arid and semiarid areas, which has severe negative effects on the morphologies and physiological processes of local plants. Therefore, drought has become one of the major abiotic stresses affecting the growth and development of plants.

As the global economy grows, especially in some regions of China, the continuous improvement of living standards makes people pay more attention to the ecological environment of urban areas, thus resulting in the great progress of urban landscaping. However, the water consumption of landscaping irrigation keeps increasing, which is in fierce competition with the water supply for agriculture, forestry and industry, especially in the regions with water shortages. This intensifies the contradiction between the shortage of water resources and the constantly increasing water demand of human beings. To realize the sustainable development of modern urban landscaping in the cruel reality of water shortages and enrich the diversity of plant communities and species in urban landscaping, landscaping practitioners have found that selection of plants with high drought-resistant is the best choice.

\footnotetext{
${ }^{*}$ Corresponding author:

Guoming Xing, Professor, College of Horticulture, Shanxi Agricultural University, Taigu, Shanxi 030801, China. E-mail: xgm@sxau.edu.cn.

Received: 12 January 2017; Revised: 20 September 2017; Accepted: 25 September 2017; Published Online: 11 October 2017
} 
The genus Iris is a winter-hardy, herbaceous perennial floral plant that includes over 300 species, distributed mostly across the northern temperate zone (Cerasela et al., 2014). As one of the important plant sources in urban landscaping, the genus Iris can make up for the deficiency of trees that grow slowly to achieve better effects of landscaping within a short term. Iris germanica is a species belonging to the genus Iris. It has large flowers in rich and bright colors and is widely used in landscaping. However, there is a high cost of conservation in the landscaping. The drought-resistant Iris germanica can effectively save manpower and water resources (Zhang and Chen, 2013). Therefore, the selection of high level of drought tolerance in Iris germanica has been one of the important factors to be considered in the allocation of plants for urban landscaping.

Currently, many scholars have provided large quantities of reports on the drought resistance of plants, mainly focus on the following fields: the condition of plant growth (Khalid, 2006; Rodriguez et al., 2005; Zhang et al., 2015b), the anatomical structures of leaves (Kutlu et al., 2009; Zhang et al., 2015a), the change of protective enzyme activity (Guan et al., 2015; Weng et al., 2015; Yang et al., 2014b) and the water metabolism and osmotic adjustment of plant tissue (Fu et al., 2016; Soltys-Kalina et al., 2016; Yasmin et al., 2013). With the constant development of more advanced apparatus for research, photosynthesis and chlorophyll fluorescence have also been applied in studies on the drought resistance of plants (Elsheery and Cao, 2008; Hassan, 2006; Liu et al., 2015; Ohashi et al., 2006; Zhang et al., 2015b).

As there are many indexes on the drought resistance of plants, the drought resistant characteristics of plants are embodied in the comprehensive results after cells under drought stress change adaptively in their morphological structures, physiology and biochemistry, as well as on the molecular level. This is a complex biological process under the effects and regulation of multiple intrinsic and extrinsic factors. Though the results of some studies are not quite the same, scholars have reached consensus on taking different aspects into consideration rather than simply using one index to reflect the drought resistance of plants. The subordination function analysis (SFA) is one common method used in the evaluation of drought resistance. However, using only SFA in the evaluation is one-sided (Shi et al., 2010). Principal component analysis (PCA) can be used to accurately determine the weight of each index, and to find a few of the principal components that can control all the variables (Karamizadeh et al., 2013). $\mathrm{Xu}$ Jun et al. (2007) hold that PCA is a data analysis method by reducing the dimensionality when large multivariate datasets are analyzed. PCA and SFA can be widely used together for drought resistance evaluation in barley (Wang et al., 2007), Lolium perenne (Shi et al., 2010), Spinacia oleracea (Shen et al., 2012), cotton (Wang et al., 2011) and marigold (Tian et al., 2011).

Previous studies of the genus Iris are mainly concentrated in pollen morphology (Oybak Dönmez and IşIk, 2008; Pinar and Dönmez, 2000), cytogenetic karyotype analysis (Karihaloo et al., 1993) and genetic diversity analysis (Azimi et al., 2012; Cerasela et al., 2014). The researches on plant resistance to salt stress and heavy metal stress also have been partly studied (Bai et al., 2008; Han et al., 2007). Though the comparative studies of the drought resistance in the genus Iris have been made previously (Shi et al., 2007), there is no report on the physiological-biochemical characteristics and the comprehensive evaluation for drought resistance in Iris germanica exposed to drought stress.

Therefore, in this study, we examined seven important physiological indexes in 10 varieties of Iris germanica before and after the drought treatment. Mathematical statistical analysis was applied to comprehensively evaluate and classify the drought resistance of iris cultivars. Stepwise regression analysis was carried out for selecting physiological indexes. Thus, the drought-resistant iris varieties that we screened can be preferentially applied to the arid areas for the landscaping. And this method for evaluating drought resistant in iris can also serve as a reference for other plants.

\section{MATERIALS AND METHODS}

\section{Plant materials}

Ten varieties of Iris germanica L. ('Purple Flower', 'Bloodstone', 'Tawny', 'Golden Baby', 'Bronze Red', 'Navigation Banner', 'Adventure', 'Dwarf Dream', 'Purple Glow' and 'White Calyx') were used in this study, which were collected from the Institute of Horticulture at Shanxi Academy of Agriculture Sciences (China, CH-SX.). The region is 'Dwb' climate zone, according to the classification of Köppens, which belongs to the north temperate continental monsoon, with annual light period length of $2402.2 \mathrm{~h}$ and the average frost-free period of $202 \mathrm{~d}$. The annual average temperature and rainfall is $9.5^{\circ} \mathrm{C}$ and $456 \mathrm{~mm}$, respectively.

\section{Malondialdehyde}

Malonadehyde (MDA) content was measured by the thiobarbituric acid (TBA) reaction (Weng et al., 2015). Approximately $0.15 \mathrm{~g}$ of the fresh leaves was homogenized in $3 \mathrm{ml}$ of $5 \%$ trichloroacetic acid (TCA) on the ice bath. The homogenate was centrifuged at $4000 \mathrm{rpm}$ for $5 \mathrm{~min}$. And $5 \mathrm{ml}$ of $0.5 \%$ TBA was added to the supernatant. The mixture was incubated (HH-M4, Herrytech Co., Ltd., Shanghai, China) at $100^{\circ} \mathrm{C}$ for $10 \mathrm{~min}$, and then quickly 
cooled on ice. The mixture was centrifuged (TG16G, Herrytech Co., Ltd., Shanghai, China) at $1000 \mathrm{rpm}$ for 5 min. Supernatant was collected and the absorbance (UV-2011, Shimadzu, CA, Japan) was monitored at $450 \mathrm{~nm}, 532 \mathrm{~nm}$ and $600 \mathrm{~nm}$. The MDA content of the leaf was calculated using the following equation: MDA content $\left(\mu \mathrm{mol} / \mathrm{g} \mathrm{F}_{\mathrm{w}}\right)=\left[6.452 \times\left(\mathrm{D}_{532}-\mathrm{D}_{600}\right)-0.559 \mathrm{D}_{450}\right]$ $\times \mathrm{V} / \mathrm{W} \times 1000$, where $\mathrm{V}$ was a volume of the supernatant.

\section{Leaf relative water content}

Leaf relative water content (RWC) was assayed as described by Cristina Patanè et al. (2016). The fresh leaves were cut and weighed. The result was recorded as fresh weight (Wf). Saturated weight $(\mathrm{Wt})$ was measured after immersing leaves in water for $24 \mathrm{~h}$, and then the leaves were oven-dried at $70^{\circ} \mathrm{C}$ for $8 \mathrm{~h}$, and reweighed. The result was recorded as dry weight (Wd); The RWC of the leaf was calculated by the formula: RWC $(\%)=[(W f-W d) /(W t-W d)] \times 100 \%$.

\section{Soluble protein}

Soluble protein (SP) content was measured by Coomassie Brilliant Blue G-250 staining (Fu et al., 2016).

\section{Rate of water loss}

Rate of water loss (RWL) from excised leaves was measured by the method of weighing (Zhang et al., 2004), with the following modifications. The fresh leaves were cut and weighed after washing by distilled water, and the result was expressed as previous weight (PW). Weight (AW) was measured after leaves were oven-dried for $1.5 \mathrm{~h}(\mathrm{~T})$ at $27^{\circ} \mathrm{C}$. The RWL was calculated by the formula: RWL $(\mathrm{g} / \mathrm{h})=(\mathrm{PW}-\mathrm{AW}) / \mathrm{T}$.

\section{Chlorophyll}

Chlorophyll (Chl) was extracted from leaves using 80\% acetone (Yang et al., 2014).

\section{Peroxidase}

The activity of peroxidase (POD) was determined by the method of guaiacol (Guan et al., 2015). The oxidation of guaiacol was monitored by the changes in absorption at $470 \mathrm{~nm}$ for $3 \mathrm{~min}(\mathrm{t})$. The reaction mixture solution contained $50 \mathrm{ml} 100 \mathrm{mM}$ PBS (pH 6.0), $19 \mu \mathrm{l} 30 \% \mathrm{H}_{2} \mathrm{O}_{2}$, $28 \mu \mathrm{l}$ guaiacol. The reaction was started by the addition of the enzyme extract to the reaction mixture solution. POD activity was calculated using the following equation: $\mathrm{POD}$ activity $\left(\Delta \mathrm{A}_{470} /\right.$ min. $\left.\mathrm{g} \mathrm{F}_{\mathrm{W}}\right)=\Delta \mathrm{A}_{470} \times \mathrm{V}_{\mathrm{T}} / \mathrm{W} \times \mathrm{V}_{\mathrm{S}} \times$ t. $\Delta \mathrm{A}_{470}$ : the changes of absorption; $\mathrm{V}_{\mathrm{T}}$ : total volume of the extracted solution; $\mathrm{V}_{\mathrm{S}}$ : volume of enzyme solution for testing; W: the weight of samples.

\section{Superoxide dismutase}

Superoxide dismutase (SOD) activity was measured by the method of nitroblue tetrazolium (NBT) (Zhang et al., 2007a). The reaction mixture solution contained
$50 \mathrm{mM}$ phosphate buffer ( $\mathrm{pH}$ 7.8), $0.1 \mathrm{mM}$ EDTA, 13 $\mathrm{mM}$ methionine, $75 \mu \mathrm{M}$ NBT, $2 \mu \mathrm{M}$ riboflavin and $100 \mu \mathrm{l}$ of the supernatant. The reactions were started under two $15 \mathrm{~W}$ fluorescent lamps, and the mixture solution without supernatant was put in the same place. The identical solutions were stored under dark place served as blanks. Illumination was stopped after $10 \mathrm{~min}(\mathrm{t})$. The absorbance was measured at $560 \mathrm{~nm}$ against the blank. SOD activity was calculated by the equation: $\mathrm{SOD}$ activity $\left(\mathrm{U} / \mathrm{g} \cdot \mathrm{h} \mathrm{F}_{\mathrm{w}}\right)=$ $\left(\mathrm{A}_{0}-\mathrm{A}_{\mathrm{S}}\right) \times \mathrm{V}_{\mathrm{T}} / \mathrm{A}_{0} \times 0.5 \times \mathrm{W} \times \mathrm{V}_{\mathrm{S}} \times \mathrm{t}$. U: the quantity of enzyme that inhibited the photoreduction by $50 \% ; \mathrm{V}_{\mathrm{T}}$ : total volume of the extracted solution; $\mathrm{V}_{\mathrm{s}}$ : volume of enzyme solution for testing; W: the weight of samples; $A_{0}$ : absorbance of contrast check; $A_{\mathrm{S}}$ : absorbance of samples.

\section{Treatments and data analysis}

The study was conducted using iris cultivars of equal size which were grown in plastic pots $(20 \times 30 \mathrm{~cm}, 10$ pots per variety and 3 plants per pot) with $2 / 3$ volume of soil mixture of $65 \%$ peat soil and 35\% surface soil in 2014 . They were grown in the greenhouse with minimummaximum temperatures of $22-28^{\circ} \mathrm{C}, 30-50 \%$ humidity and light intensity of 200,000 lux. 2 groups of the plants maintained relative soil water content of $75 \%-80 \%$ and $25 \%-30 \%$, respectively.

The center leaves of plants were taken after $0,7,14,21$ and 28 days of drought stress as test materials. Each treatment was repeated 3 times.

In this study, the results of physiological indexes were expressed as mean \pm standard deviation. The fuzzy mathematical subordination function formula was used to carry out the transformation of original test data. If an index is positively correlated to drought resistance, subordinate function values were calculated as $\mathrm{U}(\mathrm{X})=\left(\mathrm{X}-\mathrm{X}_{\min }\right) /\left(\mathrm{X}_{\max }-\mathrm{X}_{\min }\right)$; if an index is negatively correlated to drought resistance, subordinate function values were calculated as $\mathrm{U}(\mathrm{X})=1-\left(\mathrm{X}-\mathrm{X}_{\text {min }}\right) /\left(\mathrm{X}_{\max }{ }^{-}\right.$ $\mathrm{X}_{\min }$ ), where $\mathrm{X}$ indicates the value of the physiological index of the iris cultivars, $X_{\min }$ indicates the minimum value of the physiological index, and $\mathrm{X}_{\max }$ indicates the maximum value of the physiological index, and then, the software SPSS18.0 (SPSS Inc., Chicago, USA) was used to perform PCA (default method), correlation analysis (the Pearson method), CA (the furthest neighbor method) and stepwise regression analysis. Last, the proportion of the eigenvalue of each principal component in the total eigenvalue of extracted principal components was used as the weight to calculate the comprehensive evaluation value of the principal component, which was regarded as composite score (F value) for drought resistance in the iris cultivars exposed to drought stress. (Liu et al., 2013). The $F$ values of the different iris cultivars were calculated as 
$\mathrm{F}=\left(\lambda_{1} \times \mathrm{F}_{1}+\lambda_{2} \times \mathrm{F}_{2}+\lambda_{3} \times \mathrm{F}_{3}+\ldots+\lambda_{\mathrm{m}} \times \mathrm{F}_{\mathrm{m}}\right) /\left(\lambda_{1}+\lambda_{2}+\lambda_{3}+\ldots+\lambda_{\mathrm{m}}\right)$, where $\lambda_{i}(i=1, \ldots, m)$ indicates the eigenvalues of extracted principal components, and $\mathrm{F}_{1}=\mathrm{a}_{11} \mathrm{ZX}_{1}+\mathrm{a}_{21} \mathrm{ZX}_{2} \ldots+\mathrm{a}_{\mathrm{p} 1} \mathrm{ZX}_{\mathrm{p}}$; $\mathrm{F}_{2}=\mathrm{a}_{12} \mathrm{ZX}_{1}+\mathrm{a}_{22} \mathrm{ZX}_{2} \ldots+\mathrm{a}_{\mathrm{p} 2} \mathrm{ZX}_{\mathrm{p}} \ldots \mathrm{F}_{\mathrm{m}}=\mathrm{a}_{1 \mathrm{~m}} \mathrm{ZX}_{1}+\mathrm{a}_{2 \mathrm{~m}} \mathrm{ZX}_{2}+\ldots$ $+a_{p m} Z X_{p}$, where $a_{1 i}, a_{2 i}, \ldots, a_{p i}(i=1, \ldots, m)$ indicate the eigenvectors of extracted principal components, and $\mathrm{ZX}_{1}$, $\mathrm{ZX}_{2}, \ldots, \mathrm{ZX}_{\mathrm{p}}$ indicate the values of original variables that have been processed and standardized.

\section{RESULTS AND DISCUSSION}

\section{Changes in physiological indexes in response to drought stress}

Under drought stress, a series of physiological and biochemical reactions occur in plants (Liu, et al., 2005). Before drought injury or death, the variation of physiological indexes can be used to predict the impact of drought stress on plant growth (Cao et al., 2015). SP (Li et al., 2010; Mafakheri et al., 2011), Chl (Ma et al., 2004; Zaefyzadeh et al., 2009), RWC (Golparvar, 2012; Teulat et al., 2003), RWL (Zhang et al., 2004), MDA (Guan et al., 2015), SOD and POD activities (Yang et al., 2014; Weng et al., 2015) which are closely associated with drought tolerance can be used as reference indexes for evaluation of drought resistance among varieties. And these indexes have been widely utilized for the study of maize, potato, soybean and wheat drought resistance (Bano et al., 2012;
Mohammadkhani and Heidari, 2008; Paknejad et al., 2007; Wegener, et al., 2014; Zhang et al., 2007b).

In our experiment, the data shows that the different iris cultivars exposed to drought stress were with different rising amplitude on the content of MDA, SP, POD and SOD activity. The largest increasing amplitude on SOD was $104 \%$ in 'Adventure', while the least was detected in 'Purple Glow', which increased by $13.9 \%$. After drought treatment, RWL and RWC of all the iris cultivars decreased. RWC of 'Bloodstone' and 'Tawny' decreased only slightly, of these, 'Tawny' showed the smallest decrease of $3.4 \%$ and RWL of 'Golden Baby' and 'White Calyx' deceased significantly. Chl content of all the iris cultivars also changed in response to drought treatment. The largest increase in Chl content, $35.1 \%$, was observed in 'Golden Baby', while the largest decrease was in 'White Calyx', where it decreased by $32.3 \%$ (Table 1). It meant that the iris cultivars showed different responses to drought stress and different varieties had different drought resistance ability. So it was difficult to analyze which iris cultivars were better based on the above indexes. And exploring a more appropriate method is essential for further evaluation.

\section{Subordination function analysis}

Many plants grown in drought condition physiologically and morphologically exhibit various adaptive strategies to

Table 1: Changes in physiological indexes in response to drought stress in Iris germanica

\begin{tabular}{|c|c|c|c|c|c|c|c|c|}
\hline Varieties & Treatment & $\begin{array}{c}\mathrm{Chl} \\
\left(\mathrm{mg} / \mathrm{g} \mathrm{F}_{\mathrm{w}}\right)\end{array}$ & $\begin{array}{c}\text { MDA } \\
\left(\mu \mathrm{mol} / \mathrm{g} \mathrm{F}_{\mathrm{w}}\right)\end{array}$ & $\begin{array}{c}\text { POD } \\
\left(\triangle 470 / \mathrm{min}^{\prime} \mathrm{g} \mathrm{F}_{\mathrm{w}}\right)\end{array}$ & $\begin{array}{c}\text { SOD } \\
\left(U / g \cdot h F_{w}\right)\end{array}$ & RWL (g/h) & RWC (\%) & SP $(\mathbf{m g} / \mathrm{g})$ \\
\hline \multirow[t]{2}{*}{ 'Bloodstone' } & & $1.102 \pm 0.139^{a}$ & $0.041 \pm 0.007^{a}$ & $11.412 \pm 1.461^{a}$ & $357.323 \pm 31.569^{a}$ & & $95.593 \pm 2.433^{a}$ & \\
\hline & Treatment & $1.092 \pm 0.088^{a}$ & $0.056 \pm 0.034^{a}$ & $22.034 \pm 6.997^{b}$ & $419.802 \pm 74.264^{a}$ & $0.036 \pm 0.017^{a}$ & $92.098 \pm 4.306^{a}$ & 3.851 \\
\hline \multirow[t]{2}{*}{ 'Golden Baby' } & Control & $0.790 \pm 0.742^{\mathrm{a}}$ & $0.023 \pm 0.004^{a}$ & $8.222 \pm 0.779^{a}$ & $3.916 \pm 13.018^{a}$ & $0.088 \pm 0.009^{a}$ & $95.876 \pm 1$ & \\
\hline & Treatment & $1.009 \pm 0.205$ & $059 \pm 0.024^{b}$ & & & $.054 \pm 0.026^{b}$ & & \\
\hline \multirow[t]{2}{*}{ 'White Calyx' } & Control & $1.286 \pm 0.174^{a}$ & $0.063 \pm 0.007^{a}$ & $7.800 \pm 0.267^{a}$ & $130.257 \pm 10.803^{a}$ & $0.098 \pm 0.01$ & $92.816 \pm 1.547^{\mathrm{a}}$ & 2.73 \\
\hline & & $0.870 \pm 0.306^{b}$ & & & & & & \\
\hline \multirow[t]{2}{*}{ ‘Tawny’ } & Contr & $1.259 \pm 0.077^{\mathrm{a}}$ & $0.028 \pm 0.006^{a}$ & $22^{\mathrm{a}}$ & $184.018 \pm 1$ & $0.061 \pm 0.003^{a}$ & $92.734 \pm 1$ & 3.73 \\
\hline & & 1.1 & & 21. & $86^{\mathrm{b}}$ & & & \\
\hline \multirow[t]{2}{*}{ 'Dwarf Dream’ } & Cont & 1.19 & 0.08 & & 461 & & & \\
\hline & & 0.89 & 0.10 & 21.8 & $68^{b}$ & 0.0 & & \\
\hline \multirow[t]{2}{*}{ 'Purple Flower' } & & 0.93 & & & $25^{a}$ & 0.0 & $238^{a}$ & \\
\hline & Trea & 0.95 & 0.04 & 28.5 & $518.952 \pm$ & $0.04 \varepsilon$ & $467^{a}$ & 4.8 \\
\hline \multirow[t]{2}{*}{ 'Adventure' } & & 0.868 & $0.023 \pm 0.009^{a}$ & 7.667 & $229.772 \pm 1$ & 0.060 & $343^{a}$ & 3.97 \\
\hline & & 0.838 & & & & & & \\
\hline \multirow[t]{2}{*}{ 'Bronze Red’ } & Control & $1.304 \pm 0.100^{\mathrm{a}}$ & $0.052 \pm 0.008^{a}$ & $8.044 \pm 2.178^{a}$ & $343.904 \pm 20.427^{a}$ & $0.085 \pm 0.007^{a}$ & $97.043 \pm 0.856^{a}$ & $2.685 \pm 0.164^{\mathrm{a}}$ \\
\hline & & $1.166 \pm 0.262^{a}$ & $0.057 \pm 0.026^{a}$ & $15.600 \pm 5.486^{b}$ & $409.156 \pm 104.788^{a}$ & $0.059 \pm 0.022^{a}$ & & \\
\hline \multirow[t]{2}{*}{ ‘Purple Glow’ } & Control & $1.088 \pm 0.122^{\mathrm{a}}$ & $0.072 \pm 0.014^{\mathrm{a}}$ & $9.533 \pm 1.738^{a}$ & $247.671 \pm 29.657^{a}$ & $0.077 \pm 0.007^{a}$ & $91.355 \pm 1.501^{\mathrm{a}}$ & $3.728 \pm 0.292^{a}$ \\
\hline & Treatment & $0.920 \pm 0173^{a}$ & $0.087 \pm 0.011^{a}$ & $20.340 \pm 6.860^{b}$ & $282.114 \pm 83.331^{a}$ & $0.069 \pm 0.008^{a}$ & $86.462 \pm 4.339^{a}$ & $5.078 \pm 1.641^{a}$ \\
\hline \multirow{2}{*}{$\begin{array}{l}\text { 'Navigation } \\
\text { Banner' }\end{array}$} & Control & $1.317 \pm 0.084^{a}$ & $0.035 \pm 0.006^{a}$ & $9.400 \pm 2.612^{\mathrm{a}}$ & $285.353 \pm 34.676^{a}$ & $0.061 \pm 0.006^{a}$ & $90.578 \pm 1.114^{a}$ & $3.617 \pm 0.160^{a}$ \\
\hline & Treatment & $0.914 \pm 0.138^{b}$ & $0.073 \pm 0.020^{\mathrm{b}}$ & $22.556 \pm 10.557^{b}$ & $438.162 \pm 133.299^{a}$ & $0.051 \pm 0.007^{a}$ & $85.777 \pm 4.656^{a}$ & $5.410 \pm 1.042^{\mathrm{b}}$ \\
\hline
\end{tabular}

The data in the table is the average values of each treatment, the results of physiological indexes were expressed as mean \pm standard deviation, different letters between control and treatment for each variety indicate significant differences at $\mathrm{P}<0.05$ levels through paired sample $t$-test, Chl: Chlorophyll content, MDA: Malondialdehyde content, POD: Peroxidase activity, SOD: Superoxide dismutase activity, RWL: Rate of water loss from excised leaf, RWC: relative water content, SP: Soluble protein content, the same below 
the stress. Drought resistance is a complex quantitative trait affected by both genetic and environmental factors (Qin et al., 2016). Indexes of many aspects should be taken into account in the evaluation of drought resistance. The single index cannot accurately reflect the actual drought resistance of the plants. On the basis of the determination of multiple indexes, the quantitative transformation of the test data was carried out by SFA, which overcomes the one-sidedness of the single index in response to drought resistance (Zeng et al., 2016).

At present, there are many studies on the comprehensive evaluation of the resistance of plants by SFA (Cao et al., 2015; Han et al., 2006; Shi et al., 2010). In the present study, values of physiological indexes were used in SFA (Table 2). Using index of $\mathrm{Chl}$ as an example, the maximum subordinate function value was 1 for 'Tawny', while the minimum was 0 , for 'Adventure'. This suggested that when only considering index of Chl, 'Tawny' showed the highest level of drought tolerance, while 'Adventure' had the weakest drought tolerance.

\section{Correlation analysis}

Correlation analysis of physiological indexes is shown in Table 3. We found that there was a significant positive correlation between RWC and Chl content, the correlative coefficient of which was 0.843 , while there was a significant positive correlation between MDA content and RWL, the coefficient of which was 0.647 . This indicated that the decrease of RWC content in the drought stress caused the inhibition of chlorophyll synthesis, resulting in a decrease in Chl content (Paknejad et al., 2007). Meanwhile, it was pointed out that the RWL content maintained at a higher level caused damage to the cell membrane of iris cultivars, and the membrane lipid peroxidation was enhanced, leading to the increase of MDA content which was the stable metabolite of lipid peroxidation products (Weng et al., 2015).

Additionally, the remaining indexes were still correlated with each other to some extent, suggesting that the information they reflect overlaps. Consequently, if these indexes are used directly to evaluate the drought resistance of plants, the statistical results will produce a certain deviation. The similar view was also mentioned by Shi et al. (2010) that the comprehensive evaluation of drought resistance of plants using only subordinate function method also has some limitations.

\section{Principal component analysis}

PCA can avoid the interference of repeated information by converting multiple indexes into the new comprehensive and independent ones without losing original information (Zhang and Yao, 2005). In this research, values for subordinate function of seven single indexes were transformed into seven new independent principal components by PCA. Table 4 shows that contribution rate of the first three principal components are $41.337 \%$, $21.533 \%$ and $17.381 \%$, respectively. As a result, the rate of accumulation of the first three principal components reaches $80.25 \%$, which is bigger than $80 \%$. Because the first several factors could be used to reflect the original evaluation indexes unless the total amount of the data information contained in the first several factors is not less than $80 \%$ (Wang, et al., 2015). So the three principal components can be used for comprehensive evaluation of drought resistance.

As shown in Table 5, the first principle component has two characteristics that acceptably correlated with component: RWL and RWC. Each of those characteristics was both moisture characteristics for screening drought resistance (Teulat et al., 2003). So, the first principle component may be defined as comprehensive index of moisture condition. Principle component two has two characteristics that trend positively together. POD and SOD activities trend positively with each other. The activity of SOD was the only strong characteristic in principle component two. These two indexes mainly reflect active oxygen removal ability under drought stress (Yang et al., 2014). So, the principal component two may be defined as comprehensive index of active oxygen removal ability. Principle component three has one characteristic: MDA content. As one of the final products of the plant cell membrane lipid peroxide, MDA can reflect the damage degree of plant under drought stress (Weng et al., 2015). So, the principal component three may be defined as comprehensive index of damage degree.

Table 2: Values for subordinate function for Iris germanica

\begin{tabular}{lcccccccccc} 
& $\begin{array}{c}\text { Blood } \\
\text { stone }\end{array}$ & Golden Baby & White Calyx & Tawny & $\begin{array}{c}\text { Dwarf } \\
\text { Dream }\end{array}$ & $\begin{array}{c}\text { Purple } \\
\text { Flower }\end{array}$ & $\begin{array}{c}\text { Adventure } \\
\text { Bronze }\end{array}$ & $\begin{array}{c}\text { Burple } \\
\text { Red } \\
\text { Glow }\end{array}$ & $\begin{array}{c}\text { Navigation } \\
\text { Banner }\end{array}$ \\
\hline Chl & 0.7674 & 0.5166 & 0.0967 & 1.0000 & 0.1813 & 0.3565 & 0.0000 & 0.9909 & 0.2477 & 0.2296 \\
MDA & 0.7458 & 0.6949 & 0.3051 & 0.9661 & 0.0000 & 0.8983 & 1.0000 & 0.7288 & 0.2203 & 0.4576 \\
POD & 0.5745 & 0.6185 & 0.0000 & 0.5116 & 0.5636 & 1.0000 & 0.2023 & 0.1561 & 0.4643 & 0.6084 \\
SOD & 0.6851 & 0.5956 & 0.0000 & 0.2434 & 0.9827 & 1.0000 & 0.8419 & 0.6513 & 0.2477 & 0.7434 \\
RWL & 1.0000 & 0.4545 & 0.3939 & 0.4848 & 0.0909 & 0.6364 & 0.5455 & 0.3030 & 0.0000 & 0.5455 \\
RWC & 1.0000 & 0.6884 & 0.2325 & 0.7793 & 0.2480 & 0.8330 & 0.0000 & 0.8910 & 0.5039 & 0.4436 \\
SP & 0.0000 & 0.0158 & 0.4885 & 0.8598 & 0.6349 & 0.4842 & 1.0000 & 0.5670 & 0.5871 & 0.7459 \\
\hline
\end{tabular}




\section{Evaluation of drought resistance in iris cultivars}

The calculation of synthetic index is commonly utilized in the evaluation, which is convenient for comparison and statistical analysis (Shen et al., 2012; Tian et al., 2011; Wang et al., 2011). According to the mathematical model of PCA, the standardized values (Table 6 ) of original variables were

Table 3: Correlation matrix of physiological indexes in Iris germanica

\begin{tabular}{lccccccc}
\hline Indexes & Chl & MDA & POD & SOD & RWL & RWC & SP \\
\hline Chl & 1.000 & & & & & & \\
MDA & 0.439 & 1.000 & & & & & \\
POD & 0.084 & 0.137 & 1.000 & & & & \\
SOD & -0.127 & 0.161 & 0.540 & 1.000 & & & \\
RWL & 0.260 & $0.647^{\mathrm{a}}$ & 0.259 & 0.228 & 1.000 & & \\
RWC & $0.843^{\mathrm{b}}$ & 0.375 & 0.441 & 0.030 & 0.412 & 1.000 & \\
SP & -0.264 & 0.071 & -0.266 & 0.013 & -0.356 & -0.561 & 1.000 \\
\hline
\end{tabular}

${ }^{\mathrm{a} C}$ Correlation is significant at the 0.05 level (2-tailed); ${ }^{\mathrm{b}}$ Correlation is significant at the 0.01 level (2-tailed)

Table 4: Eigenvalues and contribution rate of principal components

\begin{tabular}{lccc}
\hline $\begin{array}{l}\text { Principal } \\
\text { components }\end{array}$ & \multicolumn{3}{c}{ Initial Eigenvalues } \\
\cline { 2 - 4 } & Eigenvalues & $\begin{array}{c}\text { Contribution } \\
\text { rate (\%) }\end{array}$ & $\begin{array}{c}\text { Cumulative } \\
\text { contribution } \\
\text { rate (\%) }\end{array}$ \\
\hline 1 & 2.894 & 41.337 & 41.337 \\
2 & 1.507 & 21.533 & 62.870 \\
3 & 1.217 & 17.381 & 80.251 \\
4 & 0.788 & 11.252 & 91.503 \\
5 & 0.377 & 5.380 & 96.882 \\
6 & 0.174 & 2.491 & 99.374 \\
7 & 0.044 & 0.626 & 100.000 \\
\hline
\end{tabular}

Table 5: Eigenvector matrix by principal component analysis

\begin{tabular}{lccc} 
& \multicolumn{3}{c}{ Principal component } \\
\cline { 2 - 4 } & $\mathbf{1}$ & $\mathbf{2}$ & $\mathbf{3}$ \\
\hline Chl & 0.427 & -0.418 & 0.051 \\
MDA & 0.386 & 0.027 & 0.655 \\
POD & 0.327 & 0.486 & -0.312 \\
SOD & 0.155 & 0.676 & 0.008 \\
RWL & 0.439 & 0.131 & 0.307 \\
RWC & 0.549 & -0.208 & -0.210 \\
SP & -0.338 & 0.115 & 0.576 \\
\hline
\end{tabular}

used to calculate the comprehensive evaluation value of the principal component, the result of which was regarded as composite score ( $\mathrm{F}$ value). The $\mathrm{F}$ value indicates the relative level of drought resistance in the different iris cultivars suffering drought stress. From Table 7, we can see that the highest score in the first principal component was 2.866 in 'Bloodstone', reflecting it had relatively small water deficiency after treatment. The score of 'Purple Flower' was the highest in principal component two (1.729), suggesting that the protective enzyme activities of 'Purple Flower' increased by drought stress. 'Adventure' showed the highest score of 2.294 in principal component three. That is, it avoided excessive accumulation of MDA caused by the drought and further damage for cell membrane. According to the F value, we can see that 'Purple Flower' had the maximum F value, with 'Bloodstone' taking second place, suggesting that these two varieties had the highest levels of drought resistance. 'Dwarf Dream', 'Purple Glow' and 'White Calyx' had the lowest F values, suggesting that they had the lowest levels of drought resistance. This finding basically agreed with their actual growth status.

\section{Stepwise regression analysis}

At present, large amount of drought resistance indexes was reported by relevant literatures. So it is necessary to screen out important indexes in order to select the drought resistant varieties accurately and quickly (Hu et al., 2012).

For this study, stepwise regression analysis was performed to select physiological indexes for the comprehensive evaluation of the drought resistance of the iris cultivars between the $\mathrm{F}$ value and the seven physiological indexes. The F value and seven physiological indexes were set as the dependent variable and independent variables, respectively. The optimum regression equation $\mathrm{y}=\left(-4.125 \mathrm{X}_{1}+0.010 \mathrm{X}_{2}-\right.$ $\left.2.216 \mathrm{X}_{3}\right) \times 10$ was obtained by stepwise regression analysis. In this equation, $\mathrm{X}_{1}, \mathrm{X}_{2}$ and $\mathrm{X}_{3}$ indicate three physiological indexes, namely RWL and POD and MDA, of which the direct path coefficients were $-0.387,0.446$ and -0.450 , respectively, and the determination coefficient $\mathrm{R}^{2}$ of the equation was 0.920 . It showed that the three independent variables can determine $92.0 \%$ of the total variation of the

Table 6: Standardized value of drought resistance indexes in Iris germanica

\begin{tabular}{|c|c|c|c|c|c|c|c|}
\hline Varieties & Chl & MDA & POD & SOD & RWL & RWC & SP \\
\hline 'Bloodstone' & 0.901 & 0.424 & 0.366 & 0.257 & 1.971 & 1.329 & -1.665 \\
\hline 'Golden Baby' & 0.214 & 0.274 & 0.520 & -0.010 & 0.032 & 0.384 & -1.617 \\
\hline 'White Calyx' & -0.938 & -0.872 & -1.645 & -1.791 & -0.183 & -1.000 & -0.154 \\
\hline ‘Tawny' & 1.539 & 1.071 & 0.146 & -1.064 & 0.140 & 0.660 & 0.995 \\
\hline 'Dwarf Dream' & -0.706 & -1.769 & 0.328 & 1.147 & -1.260 & -0.953 & 0.299 \\
\hline 'Purple Flower' & -0.225 & 0.872 & 1.855 & 1.199 & 0.679 & 0.823 & -0.167 \\
\hline 'Adventure' & -1.203 & 1.171 & -0.937 & 0.726 & 0.356 & -1.706 & 1.428 \\
\hline 'Bronze Red' & 1.514 & 0.374 & -1.098 & 0.156 & -0.506 & 0.999 & 0.089 \\
\hline 'Purple Glow' & -0.524 & -1.121 & -0.020 & -1.051 & -1.583 & -0.176 & 0.151 \\
\hline 'Navigation Banner' & -0.573 & -0.424 & 0.485 & 0.431 & 0.356 & -0.359 & 0.642 \\
\hline
\end{tabular}


Bo, et al.: Drought resistance of Iris

Table 7: Values for principal component and composite score for Iris germanica

\begin{tabular}{lcccccccc}
\hline Varieties & $\begin{array}{c}\text { Principal } \\
\text { component one }\end{array}$ & Rank & $\begin{array}{c}\text { Principal } \\
\text { component two }\end{array}$ & Rank & $\begin{array}{c}\text { Principal } \\
\text { component three }\end{array}$ & Rank & Composite score & Rank \\
\hline 'Bloodstone' & 2.866 & 1 & -0.223 & 6 & -0.421 & 7 & 1.325 & 2 \\
'Golden Baby' & 1.136 & 3 & -0.097 & 5 & -0.974 & 8 & 0.348 & 4 \\
'White Calyx' & -2.131 & 10 & -1.477 & 10 & -0.054 & 5 & -1.506 & 10 \\
'Tawny' & 1.041 & 4 & -1.268 & 8 & 1.204 & 2 & 0.457 & 3 \\
'Dwarf Dream' & -1.876 & 9 & 1.250 & 2 & -1.304 & 10 & -0.913 & 8 \\
'Purple Flower' & 1.840 & 2 & 1.729 & 1 & -0.071 & 6 & 1.396 \\
'Adventure' & -1.517 & 7 & 1.134 & 3 & 2.294 & 1 & 0.020 \\
'Bronze Red' & 0.751 & 5 & -1.315 & 9 & 0.352 & 3 & 7 \\
'Purple Glow' & -1.669 & 8 & -0.685 & 7 & -1.126 & 9 & -1.287 \\
'Navigation Banner' & -0.440 & 6 & 0.951 & 4 & 0.100 & 4 & 5 & 0.050 \\
\hline
\end{tabular}

F value that was 23.122, and the equation was significant. From the regression equation, it can be seen that POD activity and RWL, MDA of seven physiological indexes had a significant influence on the $\mathrm{F}$ value of the drought resistance of the iris cultivars, which meant they can be used as important indexes for the comprehensive evaluation of the drought resistance of the iris cultivars. The correlation analysis on the $F$ value and the predicted value obtained by calculation with this regression equation showed that the correlation coefficient was $0.959(\mathrm{P}<0.01)$. This suggested that the equation can be used as a simple method to make a comprehensive evaluation of the drought resistance of the iris cultivars comparable accurately. Based on this method, the different formula was found by Hu et al. (2012) in rice who reported the equation can be used for comprehensive evaluation and the reliability reached $97.1 \%$. However, since the formulas were constructed in the particular experimental conditions, the establishment of the formulas needed to have strict control conditions.

\section{Clustering analysis}

Cluster analysis was applied to objectively classify the iris cultivars based on their $\mathrm{F}$ values. With the furthest distance method, the 10 iris cultivars were clustered into three groups at a Euclidean distance of 12.02 (Fig. 1). Two iris cultivars were placed in group I, including 'Purple Flower' and 'Bloodstone'; 'Tawny', 'Golden Baby', 'Bronze Red', 'Navigation Banner' and 'Adventure' were in group II; and the remaining three varieties, 'Dwarf Dream', 'Purple Glow' and 'White Calyx', were in group III. According to the $\mathrm{F}$ values of the groups, 10 iris cultivars were divided into three groups namely drought-resistance group (I), medium drought-resistance group (II), and low droughtresistance group (III). Of these, 'Purple Flower' and 'Bloodstone' were with the highest $\mathrm{F}$ value and clustered in the drought-resistance group, demonstrating that they had the highest drought resistance capability and were two drought resistance varieties. Interestingly, we found that there was a big difference of superficial morphology between the two drought-resistant varieties. Therefore,

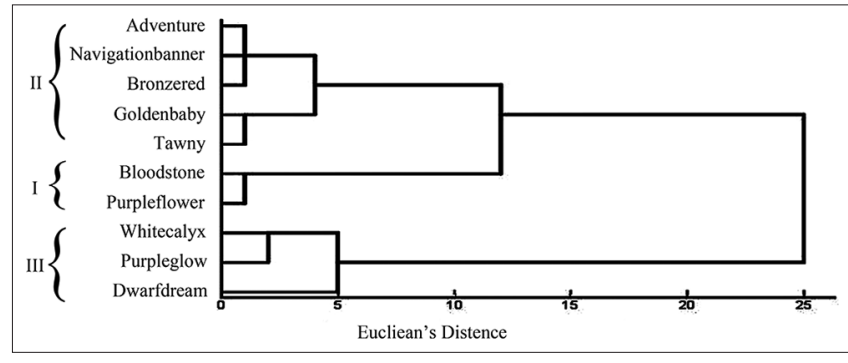

Fig 1. Cluster analysis of 10 iris cultivars based on $\mathrm{F}$ value

the drought resistance of iris could not only be identified from the apparent forms. In addition, on account of the same area which they came from, the region maybe has an impact on their drought resistance.

\section{CONCLUSIONS}

In summary, the results from our study revealed that drought stress induced in the increasing of MDA and SP content, SOD, POD activities. Decreased of RWC and RWL were observed in leaves when suffering drought stress. Chl content of all the iris cultivars also changed in response to drought treatment. After the subordinate function values of the physiological indexes were calculated, PCA was utilized to comprehensive evaluate the drought resistance of the iris cultivars in the research. Seven single indexes were transformed into three principal components, namely comprehensive index of moisture condition, active oxygen removal ability and damage degree. The composite score ( $F$ value) of the iris drought resistance was obtained. Meanwhile the stepwise regression analysis suggested that POD activity and RWL, MDA can be used as important indexes to comprehensively evaluate the drought resistance of iris cultivars, and drought resistance of iris cultivars can be evaluated using this formula in general. Ultimately, based on the CA results, the 'Purple Flower' and 'Bloodstone' were clustered in the drought-resistance group, suggesting that they had the highest drought resistance capability and were two drought tolerant iris varieties, which can be 
used by breeders for the genetic improvement of drought resistance in other iris cultivars and provide greening plants for the landscape architecture construction in arid area. And also, our study will provide a reasonable method for drought resistance evaluation in iris and other plants.

\section{ACKNOWLEDGEMENTS}

This research was conducted in Institute of Horticulture, Shanxi Academy of Agricultural Sciences, Taiyuan, China. This research was supported by research grants from Fund Program of Financial Support for Agriculture of Shanxi Province, China (2015ZZCX-11). We gratefully thank our research team for their helps on data processing and suggestions to improve experimental design.

\section{Author contributions}

G. Xing conceived and designed the experiments. W. Bo, B. $\mathrm{Fu}$ and G. Qin performed the experiments. W. Bo and Y. Wang analyzed the data. W. Bo and G. Xing wrote the paper.

\section{REFERENCES}

Azimi, M. H., S. Y. Sadeghian, V. R. Ahari, F. Khazaei and A. F. Hafashjani. 2012. Genetic variation of Iranian Iris species using morphological characteristics and RAPD markers. Int. J. Agric. Sci. 2(9): 875-889.

Bai, W., P. Li, B. Li, H. Fujiyama and F. Fan. 2008. Some physiological responses of Chinese Iris to salt stress. Pedosphere. 18(4): 454-463.

Bano, A., F. Ullah and A. Nosheen. 2012. Role of abscisic acid and drought stress on the activities of antioxidant enzymes in wheat. Plant Soil. Environ. 58(4): 181-185.

Cao, X., F. Jiang, X. Wang, Y. Zang and Z. Wu. 2015. Comprehensive evaluation and screening for chilling-tolerance in tomato lines at the seedling stage. Euphytica. 205: 569-584.

Cerasela, P., L. Simona, V. Giancarla, D. Marcel, L. Alexandru, C. Iuliana and B. Maria. 2014. Genetic stability of micropropagated Iris germanica L. varieties assessed by RAPD markers. Rom. Biotech. Lett. 19(5): 9778-9784.

Elsheery, N. I. and K. Cao. 2008. Gas exchange, chlorophyll fluorescence, and osmotic adjustment in two mango cultivars under drought stress. Acta Physiol. Plant. 30(6): 769-777.

Fu, L., Z. Ding, B. Han, W. Hu, Y. Li and J. Zhang. 2016. Physiological investigation and transcriptome analysis of polyethylene glycol (PEG)-induced dehydration stress in cassava. Int. J. Mol. Sci. 17(3): 283-301.

Golparvar, A. R. 2012. Assessment of drought stress effects on RWC and chlorophyll content in rapeseed cultivars (Brassica napus L.). Tech. J. Engin. Appl. Sci. 2(11): 404-407.

Guan, G., Y. Wang, H. Cheng, Z. Jiang and J. Fei. 2015. Physiological and biochemical response to drought stress in the leaves of Aegiceras corniculatum and Kandelia obovata. Ecotoxicology. 24(7): 1668-1676.

Han, R., X. Lu, G. Gao and X. Yang. 2006. Analysis of the principal components and the subordinate function of alfalfa drought resistance. Acta Agrestia Sin. 14(2): 142-146.

Han, Y., H. Yuan, S. Huang, Z. Guo, B. Xia and J. Gu. 2007. Cadmium tolerance and accumulation by two species of Iris. Ecotoxicology 16(8): 557-563.

Hassan, I. A. 2006. Effects of water stress and high temperature on gas exchange and chlorophyll fluorescence in Triticum aestivum L. Photosynthetica. 44(2): 312-315.

Hu, B., Y. Wan, X. Li, J. Lei, X. Luo, W. Yan and J. Xie. 2012. Analysis on genetic diversity of phenotypic traits in rice (Oryza sativa) core collection and its comprehensive assessment. Acta. Agron. Sin. 38(5): 829-839.

Huang, J., H. Yu, X. Guan, G. Wang and R. Guo. 2016. Accelerated dryland expansion under climate change. Nat. Clim. Change. 6(2): 166-171.

Karamizadeh, S., S. M. Abdullah, A. A. Manaf, M. Zamani and A. Hooman. 2013. An overview of principal component analysis. J. Signal Inform. Process. 4(3B): 173-175.

Karihaloo, V., J. L. Karihaloo and A. K. Koul. 1993. Structural heterozygosity in Iris variegata L. Caryologia. 46(1): 77-85.

Kawai, T., Y. Tada, M. Shinoda, R. Tsuchiya, T. Morii, T. Suzuki and K. Tseedulam. 2014. Simple method of shallow groundwater exploration by groundwater aeration sound in semi-arid grassland. J. Arid Land Stud. 24(1): 245-248.

Khalid, K. A. 2006. Influence of water stress on growth, essential oil, and chemical composition of herbs (Ocimum sp.). Int. Agrophysics. 20(4): 289-296.

Kutlu, N., R. Terzi, Ç. Tekeli, G. Şenel, P. Battal and A. Kadioğlu. 2009. Changes in anatomical structure and levels of endogenous phytohormones during leaf rolling in Ctenanthe setosa under drought stress. Turk. J. Biol. 33(2): 115-122.

Li, D., C. Li, H. Sun, W. Wang, L. Liu and Y. Zhang. 2010. Effects of drought on soluble protein content and protective enzyme system in cotton leaves. Front. Agric. China. 4, 56-62.

Liu, Q., H. Sun and D. He. 2005. Plant responses to the high temperature and moisture stress. J. China West Normal Univ. Nat. Sci. Ed. 26(4): 364-368.

Liu, T., M. Sheng, C. Wang, H. Chen, Z. Li and M. Tang. 2015. Impact of arbuscular mycorrhizal fungi on the growth, water status, and photosynthesis of hybrid poplar under drought stress and recovery. Photosynthetica. 53(2): 250-258.

Liu, Z., C. Zhang and G. Zhou. 2013. Study on principal component analysis of residents happiness index. JDCTA. 7(6): 593-600.

Ma, C., Q. Li, Y. Gao and T. Xin. 2004. Effects of silicon application on drought resistance of cucumber plants. Soil Sci. Plant Nutr. 50(5): 623-632.

Mafakheri, A., A. Siosemardeh, B. Bahramnejad, P. C. Struik and Y. Sohrabi. 2011. Effect of drought stress and subsequent recovery on protein, carbohydrate contents, catalase and peroxidase activities in three chickpea (Cicer arietinum) cultivars. Aust. J. Crop Sci. 5(10): 1255-1260.

Mohammadkhani, N. and R. Heidari. 2008. Effects of drought stress on soluble proteins in two maize varieties. Turk. J. Biol. 32(1): 23-30.

Ohashi, Y., N. Nakayama, H. Saneoka and K. Fujita. 2006. Effects of drought stress on photosynthetic gas exchange, chlorophyll fluorescence and stem diameter of soybean plants. Biol. Plant. 50(1): 138-141.

Oybak, D.E. and S. Işlk. 2008. Pollen morphology of Turkish Amaryllidaceae, Ixioliriaceae and Iridaceae. Grana. 47(1): 15-38.

Paknejad, F., M. Nasri, H. R. T. Moghadam and H. Zahedi. 2007. Effects of drought stress on chlorophyll fluorescence parameters, chlorophyll content and grain yield of wheat cultivars. J. Biol. Sci. 7(6): 841-847.

Parr, J. F., R. I. Papendick, S. B. Hornick and D. Colacicco. 1989. 
Use of organic amendments for increasing the productivity of arid lands. Arid Soil Res. Rehabil. 3(2): 149-170.

Patanè, C., D. Scordia, G. Testa and S. L. Cosentino. 2016. Physiological screening for drought tolerance in Mediterranean long-storage tomato. Plant. Sci. 249: 25-34.

Pinar, N. M. and E. O. Dönmez. 2000. Pollen morphology of Turkish Iris L. (Iridaceae) with reference to evolutionary trends at the infrageneric level. Isr. J. Plant Sci. 48(2): 129-141.

Qin, P., Y. Lin, Y. Hu, K. Liu, S. Mao, Z. Li, J. Wang, Y. Liu, Y. Wei. and Y. Zheng. 2016. Genome-wide association study of droughtrelated resistance traits in Aegilops tauschii. Genet. Mol. Biol. 39(3): 398-407.

Rodriguez, P., A. Torrecillas, M. Morales, M. Ortuno and M. Sanchezblanco. 2005. Effects of $\mathrm{NaCl}$ salinity and water stress on growth and leaf water relations of Asteriscus maritimus plants. Environ. Exp. Bot. 53(2): 113-123.

Shen, D., X. Liu, D. Tang and D. Huang. 2012. Germination characteristics and heat tolerance in seeds of Spinacia oleracea L. Under various high-temperature stresses. J. Shanghai Jiaotong Univ. Agric. Sci. 30(4): 31-38.

Shi, X., P. Mao, G. Zhang and L. Meng. 2007. The comparison of drought resistance on 15 Chinese Iris germplasm at seedling stage. Acta. Agrestia Sin. 15(4): 352-358.

Shi, Y., L. Wan, J. Liu, Y. Wang, R. Guo, X. Wu and X. Li. 2010. Analysis of the principal components and the subordinate function of Lolium perenne drought resistance. Acta Agrestia Sin. 18(5): 669-672.

Soltys-Kalina, D., J. Plich, D. Strzelczyk-Zyta, J. Sliwka and W. Marczewski. 2016. The effect of drought stress on the leaf relative water content and tuber yield of a half-sib family of ‘Katahdin'-derived potato cultivars. Breed Sci. 66(2): 328-331.

Teulat, B., N. Zoumarou-Wallis, B. Rotter, S. M. Ben, H. Bahri and D. This. 2003. QTL for relative water content in field-grown barley and their stability across Mediterranean environments. Theor. Appl. Genet. 108(1): 181-188.

Tian, Z., F. Wang, W. Zhang and X. Zhao. 2011. Drought-resistance evaluation of marigold cultivars based on multiple statistics analysis. Chin. J. Appl. Ecol. 22(12): 3315-3320.

Wang, J., M. Zhou, R. Xu, C. Lu and Z. Huang. 2007. Studies on selecting indices and evaluation methods for barley's (Hordeum vulgare L.) waterlogging tolerance. Sci. Agric. Sin. 40(10): 2145-2152.

Wang, J., W. Ye, D. Wang, W. Fan and S. Wang. 2011. Germination characteristics and comprehensive evaluation of drought resistance of 41 accessions of cotton germplasm at seed germination stage under PEG-6000 stress. J. Plant Genet. Resour. 12(6): 840-846.

Wang, L., G. Liu and S. Li. 2015. Comprehensive groundwater quality assessment in deyang area of sichuan. Environ. Sci. Technol. 38(s2): 411-414.

Wegener, C. B., G. Jansen and H. U. Jurgens. 2014. Influence of drought and wounding stress on soluble phenols and proteins in potato tubers. SAR. 3(3): 1-15.

Weng, M., L. Cui, F. Liu, M. Zhang, L. Shan, S. Yang and X. Deng. 2015. Effects of drought stress on antioxidant enzymes in seedlings of different wheat genotypes. Pak. J. Bot. 47(1): 49-56.

Xu, J., J. Xia and Q. Li. 2007. Database cluster preprocessing with principal component extraction. J. Shanghai Univ. Nat. Sci. 13(6): 705-710.

Yang, J., X. Zhang, Y. Peng, L. Huang, X. Liang, K. Wang, G. Yin and X. Zhao. 2014a. Osmolyte accumulation, antioxidant enzyme activities and gene expression patterns in leaves of orchardgrass during drought stress and recovery. Grassl. Sci. 60(3): 131-141.

Yang, P., Q. Huang, G. Qin, S. Zhao and J. Zhou. 2014b. Different drought-stress responses in photosynthesis and reactive oxygen metabolism between autotetraploid and diploid rice. Photosynthetica. 52(2): 193-202.

Yasmin, H., A. Bano and S. Ullah. 2013. Sceeening of PGPR isolates from semi-arid and their implcation to alleviate drought stress. Pak. J. Bot. 45(SI): 51-58.

Zaefyzadeh, M., R. A. Quliyev, S. M. Babayeva and M. A. Abbasov. 2009. The effect of the interaction between genotypes and drought stress on the superoxide dismutase and chlorophyll content in durum wheat landraces. Turk. J. Biol. 33(1): 1-7.

Zeng, H., G. Wen, X. Luo, L. Zeng, L. Wang and J. Xu. 2016. Comprehensive evaluation of four light green roof plants on drought resistance. Pratacultur. Sci. 33(6): 1084-1093.

Zhang, C. and W. Chen. 2013. Physiological-ecological responses of Iris germanica L. to Cd stress and its accumulation of Cd. Acta Ecol. Sin. 33(7): 2165-2172.

Zhang, F., K. Zhang, C. Du, J. Li, Y. Xing, L. Yang and Y. Li. 2015a. Effect of drought stress on anatomical structure and chloroplast ultrastructure in leaves of sugarcane. Sugar Tech. 17(1): 41-48.

Zhang, F., Y. Wang, Z. Lou and J. Dong. 2007a. Effect of heavy metal stress on antioxidative enzymes and lipid peroxidation in leaves and roots of two mangrove plant seedlings (Kandelia candel and Bruguiera gymnorrhiza). Chemosphere. 67(1): 44-50.

Zhang, M., L. Duan, X. Tian, Z. He, J. Li, B. Wang and Z. Li. 2007 b. Uniconazole-induced tolerance of soybean to water deficit stress in relation to changes in photosynthesis, hormones and antioxidant system. J. Plant Physiol. 164(6): 709-717.

Zhang, M., Z. Peng, B. Xie, F. Tan, Q. Zang, Y. Fu, C. Yang and Y. Yang. 2004. Relationship between water loss rate of cutting leaves and osmotic regulators under water stress and drought resistance in sweet potato. Sci. Agric. Sin. 37(1): 152-156.

Zhang, T., Y. Cao, Y. Chen and G. Liu. 2015b. Non-structural carbohydrate dynamics in Robinia pseudoacacia, saplings under three levels of continuous drought stress. Trees. 29(6): 1837-1849.

Zhang, Z. and Q. Yao. 2005. Application of the principle component analysis on mango storage characteristic. Subtrcpical Plants Sci. 34(2): 25-28. 